\title{
Students as partners in blending learning
}

\section{Paul Brett}

University of Wolverhampton, UK

\section{Glynis Cousin}

University of Wolverhampton, UK

\begin{abstract}
In this paper we argue for university pedagogies to be in tune with the ways in which many of the present generation of students interact with technologies. We propose that the technical expertise and the novel modes of being which are characteristic of this generation offer radical pedagogic possibilities for growing learner engagement. In making this proposal, we suggest a reconfiguration of curriculum design in order to foreground students' expertise with technology, particularly Web 2.0. We propose that these capabilities be deployed in partnership with academics. The paper maps out the conceptual terrain and reports on the first cycle of action research projects which have been designed to trial the reconfiguration we suggest. Early findings indicate seven particular and differential ways in which students have profited from this reconfiguration, most notably through the use of peer-led Facebook groups as a hub and a means of peer support.
\end{abstract}

An earlier version of this paper was presented at the Seventh International Conference on Networked Learning, Aalborg, Denmark, 3rd and 4th May 2010.

Keywords: student control; Web 2.0; social networking; diversity and widening participation; blended learning; curriculum design; new generation learners; partnerships between academics and students. 


\section{Introduction - reconfiguring power in blended learning}

The reconfiguration of the relationship between students, teachers and technologies we propose affects four, related, $180^{\circ}$ changes to the power axes of blended learning. Namely that: (i) the choice and ownership of the technologies used should be the learners; (ii) this choice be from common, freely available, student understood technologies which are in the public domain; (iii) that the decisions about what technological learning opportunities are rendered are taken by students in partnership with academics; and (iv) that the production of these opportunities be done by incentivised students.

\section{The rationale}

There are three imperatives determining these reconfigurations. Firstly, integration of the use of technology in higher education (HE) courses is inconsistent and lacks reach (Newland et al., 2006; Sharpe et al., 2006, p.62; Lingard, 2007). The barriers to staff use of Virtual Learning Environments (VLE) have remained constant over four Universities and Colleges Information Systems surveys, dating back to 2002. Reported in order of frequency these are: lack of time; lack of academic staff knowledge; lack of money; institutional culture; lack of support staff; lack of recognition for career development; lack of academic staff development; and lack of incentives (Browne et al., 2008, p.27). We suggest that the solution to this is held with our students, rather than staff.

Next, with the changed nature of the network, characterised as Web 2.0, universities are destined to chase forever their tail in keeping up with and exploiting technological advances with their possible learning potentials. Student skill sets invite a different way of chasing. The impact of Web 2.0 on HE is yet to be realised, or completely understood, although studies of the use of collaborative Web 2.0 tools are well underway e.g. Minocha (2009) and Trentin (2009) with wikis, Kerawalla et al. (2009) with blogs, Hemmi et al. (2009) with weblogs and wikis, and Cann (2008) with social networking tools. There has also been useful discussion of the tensions which may arise (Dohn, 2008; Ryberg, 2008) when such tools are used to support institutional learning. Add to this the changes in connectivity which see near ubiquitous student ownership of mobile web-enabled devices. This forms another constitutive part of the new generation of learners' worlds (see Traxler 
2009 for an overview). Later, we discuss our action research into how student-led use of Web 2.0 software contributes to enhanced support for student learning.

Thirdly, and somewhat contentiously, are the different cognitive skills characteristics of our younger learners, variously typified as 'digital natives' (Prensky, 2001), 'New Millennium Learners' (CERI, 2008), 'transliterate' (Fearn, 2008) and 'Generation M' (Cvetkovic and Lackie, 2009). The CERI report on New Millennium Learners (2008) usefully synthesises the research into the impact of engagement with technology. It characterises the findings as both controversial and provisional. The report states that in those areas of cognitive ability which relate directly to educational performance such as abilities related to...information processing, reflective and critical thinking, creativity and, in general, metacognitive skills...' (CERI, 2008, p.7) there are no conclusive findings. However, the report concludes that in cognitive skills development '...visual-spatial skills, the Flynn effect (nonverbal intelligence), memory skills, and to a lesser extent multitasking' (CERI, 2008, p.8) there is conclusive evidence to suggest that technology use influences these capacities. Clearly, many of our learners are able to multi-task with a variety of different technologies, expert at accessing and controlling information, preferring the pictorial to text, adept at socialising virtually, and always connected to the network. While these findings remain disputed in relation to the effects of technology on cognitive development, clearly this generation of students is immersed in communication technology in ways that were not available to former generations. It is precisely this immersion that supports the case for the power reconfigurations outlined above.

We believe that the radical inversion of both the locus of responsibility, from teacher to student with teacher, and from institutionally owned technology to that which is student chosen, has the potential to transform the quality of current learning. Academics' awareness of the vibrant network landscape and its associated tools is likely to be less well developed than that of most students, who should be able to select and use appropriate technologies which may have greater functionality than our VLE. But many need help in doing so. While our students are acquiring the skills of transliteracy, Fearn (2008) observes: 
...many academics are in essence illiterate... Most would admit it, even taking a certain pride in their part-removal from the world of e-communication. This matters if they find their teaching relationship with hyper-transliterate students breaking down because of an inability to communicate fully with one another.

What do all the above suggest for our conceptions of curriculum design and e-learning as an aspect of the blending of our students' learning? We finish with a brief outline of the action research which explores our hunch that establishing curriculum design partnerships between students and teachers will ensure: a) that we fully profit from the expertise and ways of learning of our students; b) that we move with the technology; and c) that the partnerships reconfigure teacher-student relationships, increasing the meaningfulness of the learning for a diverse student population.

\section{Student as partners in blended learning curriculum design and learning activities: action research, an initial exploratory study}

\section{Rationale}

Our action research addresses these pressing issues of growing discord between students and academics, particularly in relation to the diverse groups coming into our universities for whom, according to Hockings et al. (2007), there is already a fragile relationship with traditional academe. In exploring the transfer of responsibility for selection and managing technology, we see our research as building on Cann's $(2008$, p.2) aim 'to develop new practical strategies for deployment of "... loosely coupled teaching" involving Web 2.0 tools to facilitate and promote personal development planning and lifelong learning'. We are also building on early explorations of the nature of the tensions and deficits which may arise (Dohn, 2008; Ryberg, 2008) when institutions appropriate social networking technologies, and the suggestion by Melville $(2009$, p. 9) that:

Higher education has a key role in helping students refine, extend and articulate the diverse range of skills they have developed through their experience of Web 2.0 technologies. It not only can, but should, fulfill this role, and it should do so through a partnership with students to develop approaches to learning and teaching. 


\section{Context}

Our project was configured to enact the four, $180^{\circ}$ changes to the operation of blended learning's curriculum design and learning activities, described above. It involved a second year, semester two, Computer Studies module Managing IS and IT, which had 64 students enrolled, and a first year semester two Applied Sciences module Health and Disease, which had 216 students enrolled. Each had a different member of academic staff and a diverse student population, typical for our institution. As with most universities, the academics at Wolverhampton are responsible for the design of the 'e' learning support side of the blended learning in modules and for the implementation and technical rendering of these choices. Unsurprisingly, the levels of sophistication they bring to this task vary enormously, with some using the institutional VLE as a simple repository of course documentation to others offering rich forms of e-learning. Our change intervention is designed to leap over this variation by placing the authority to choose the technologies and their application to learning in the hands of partnered students.

The 'action' part of our action research centres on two key change interventions across these two modules. We appointed two student 'e-champions' for the Managing IS and IT module and three for the larger Health and Disease module, in consultation with their module tutor, whose prior consent we secured. These e-champions were briefed to shape and lead ' $e$ ' support for their module colleagues, in partnership with the module leader. We gave them $£ 75$ each as some form of recognition of the work they would do. The selection process required that e-champions apply for the position and their involvement had the same status as a volunteer in any peer supported scheme. Their appointment and their role was announced in the class by the module leader.

So what did we find? Our evidence came from six sources, namely: what they did; an analysis of progression; an analysis of the Facebook exchanges; a survey of the students on the module; and interviews with lecturers and with the five student e-champions.

\section{What did the student e-champions do and produce?}

Both e-champion teams created closed Facebook groups and invited colleagues to join in the classes. Tutors and the researchers were asked to join and did, but they did not post. The Health and Disease team set up a blog, wrote some extra learning materials, and with the module leader wrote formative assessment questions with answers. The Managing IS 
and IT module tried Twitter. Both sets of e-champions attempted to video record the taught sessions and post their links, but experienced insurmountable problems and this was abandoned in week 3 . Both also researched and posted additional sources of information through links from the Facebook groups. The e-champions also had regular meetings with the module leaders.

\section{What evidence is there that these activities engaged students?}

In the Health and Disease module of the enrolled 216 students, $47.5 \%$ joined the studentled Facebook group. There were 129 entries in this, with 26 posts on the Facebook Wall from students other than the e-champions. It is not possible to know how many students read these interchanges. There were 18 posts to the Discussion area of Facebook. Interestingly, the e-champions used this area of Facebook to document their interactions with the module leader and to describe what they were doing. Eight links to sources of additional information, notes and formative assessment questions were posted. They set up a blog. It was used to distribute: (i) a glossary of complex terms; (ii) formative assessment questions with answers; and (iii) extra learning materials on one of the module's topics, all researched and written by the e-champions. In the Managing IS and IT module, 21 of the 64 enrolled students (33\%) joined the Facebook group. There were 29 entries with posts from 7 students other than the e-champions on the Facebook Wall. There were 10 posts to four topics on the Discussion area of Facebook. These were attempts to start discussions by the e-champions. The e-champions were also were given a Forum in the module's VLE, to which they made 16 posts with links to extra resources. There were no replies to their posts. The Twitter group attracted only 7 followers and was discontinued after 7 tweets.

\section{Analysis of progression}

There are promising signs that the intervention can make a difference to pass and progression rates. When compared with past patterns of achievement the module Health and Disease exhibited a $10 \%$ increase in pass rates. In the Managing IS and IT module progression and achievement stayed the same as previous years. From their own testimonies, the intervention certainly increased the e-champions' engagement in learning. 
'A' grades were attained by the two Managing IS and IT e-champions and by those in the Health and Disease module.

\section{Facebook exchanges - analysis of the interactions}

The richest data source came from our analysis of the Facebook exchanges. We have generated seven categories, each showing a different type of learning support, from our analysis of the interchanges and postings in the student-led Facebook groups. These are described below with examples taken verbatim from the Facebook posts.

\section{Creating, extending and sharing learning content}

Both sets of e-champions used the role and the Facebook space to create and provide additional learning content. An example of student e-champion (STEC) created content is:

STEC 3: Hi, this is blog created by e-champions that will the glossary of some complex terms which you might have come across in you lectures. It will be available through this link for a week. http://...

Other content sources were supplied through links:

STEC 2: If you are interested in finding out more about the Security in Cloud computing. Read ...

The Health and Disease e-champions researched the topic of epidemiology in depth, typed up notes and made them available via a link on Facebook. The Managing IS and IT e-champions were given their own Forum in the VLE which they used to post 16 links to additional learning content. These links were viewed on 265 occasions by 38 of the students, with 26 students not viewing any of these posts. None of these additional sources of learning content would have been made available without the e-champions. 


\section{Mediating between students and staff}

The e-champions evolved into mediators between their peers and teaching staff. This process was supported in Facebook:

STEC 3: Hello students, I just wanted to say for the student who stated that they would like to have more clear explanations on the graphs and diagrams that were presented in Dr. XXX 's lecture, i have sent a message to him regarding this and hopefully he should reply back soon and i will let you all know what he says.

As another example:

STEC 1: Questions from lecture $416 / 03 / 10$ These are the questions that have come from the students regarding the Prevention and treatment lecture on 16/03/10. Those of you who did not put academic questions forward but actual questions on ideas for this module I will put forward to Dr. XXX and then I will give feedback to everyone on what they were and what the lecturers had to say about them.

This mediation benefited the staff as well (discussed below).

\section{Peer support to fill in gaps in understanding of content}

There were interchanges where students posted specific questions on aspects of the module content. For example:

Student X: In Dr XXX's 1st lecture there is a slide titled FAT (TRIACYLGLYCEROL) I'm struggling making sense of it. Is it stating glycogen is $6 x$ as energy dense or fat? Is it referring to calories? Im curious as other sources are claiming fat is $9 x$ as energy dense. Can someone please explain.

As another example:

Student D: hello guys, can anyone answer to the questions below pls? 1,From the alphabetical list below, which is the correct order of the levels of protein structure?
A. Hexagonal
B. Primary
C. Quaternary
D. Secondary
E. Tertiary F. Ziggurat... 
To which the STEC 2 replied:

STEC 2: hi, dear friend, Primary structure of protein refers to the sequence of amino acid in the polypeptide chain that makes up protein. The structure and shape of entire protein chain makes secondary, tertiary and so on...

We wonder what would have happened to such questions without the Facebook group? However, this also raises a couple of questions. What if the e-champions had replied incorrectly, and were the posters just being lazy? It might be that students are more willing to share concerns or understanding gaps with fellow students, than directly with staff. The use of a student-led and owned social network space, rather than an institutionally owned technology may also have assisted sharing of such knowledge deficits.

\section{Peer support to fill in the gaps in understanding of administration processes}

Posts with questions about administration procedures from the students and proactive, partnering posts about required administration actions from the e-champions were present in both Facebook groups. For example:

Student Q: Anyone know how we submit the front sheet if we have done the assignment in powerpoint...?

STEC 4: see if you can convert your powerpoint file onto word.... lot of students are having similar problems.

Where would such questions have been asked without the Facebook page? As another proactive example:

STEC 2: The SWOT Analysis presentation from FDM is tomorrow for those of you attending contact Placement office for details. 


\section{Creating formative assessment learning activities}

The Health and Disease e-champions took it upon themselves to create multiple choice questions for a couple of topics in their module, in partnership with the module tutor. These were created in Word and made downloadable from another website (as Facebook does not support the posting of Word documents), with the link posted in the Facebook group. They supplied the answers the following week. For example:

STEC 4: Hello all, as promised we are working alongside with the module team to get this group going. we have created a bolg which is up for a week. there are some questions which you can do as a homework. Answers to these questions will be posted next week.

Their reasons for doing this are in the student interview section, below. Obviously this would have been a rich resource, but we do not know how many students engaged with it. This is an excellent example of a partnership, with the e-champions defining the need and supplying the technical expertise, and the academic assuring the quality of the formative assessment.

\section{Rescuing peers and supporting each other}

Some students shared their personal situations, concerns and needs in Facebook posts. As examples:

Student K: Oh my God this page is a godsend!!! ...l've been unwell and missed some lectures so this is brilliant!! Keep up the good work :)

Student F: Hi, I didn't know about this group until the message on WOLF. It's great coz I am missing a few lectures due to illness :( but if you could keep posting it would help me loads! and it's great revision :).

Experiences were posted and shared, for example:

STEC 4: Do any of you suffer from the syndrom of feeling shy to ask questions during lectures, for fear of looking stupid in front of everyone, even though you have no clue in the world what the past hour was all about? 
Student Y: ... it happens but I personally do not mind because I have to ask those questions as part of my learning. I do think that the lectures gets more interesting when students ask questions.

Being able to share personal fears and issues is likely to be a first step in their resolution. Student e-champions and peers may be able to suggest solutions, but many may well need professional interventions.

\section{Sharing ideas about how to learn}

The students also shared their views on what helped them learn, and with the support of the academic, what would be helpful approaches to learning. For example, after meeting the lecturer STEC 1 posted:

STEC 1: The point here is that the lecturers want us students to be encouraged to do background/further reading around the subjects.

Student D advised on the use of the Facebook group page that:

Student D: ... it's just a case of offering that help really, if you offer that help you will find there will be a lot more regular users. Try it out by setting up a few topics on lets say bacteria and viruses and see if people use them...i know i will lol.

The e-champions solicited ideas about what would help learning, for example:

STEC 4: We are welcome and eager to hear any suggestions from yourselves of how your learning can be improved through the use of the various technologies available if need be you can contact ...

And fed the replies into their meetings with lecturers. 


\section{Survey of the students on the module}

Responses to open-ended questions in an e-survey sent to all module participants asking for responses to the student e-champion initiative were very poor. However, we could only find one student, from the 17 responders, who confirmed the JISC Learner Experiences project (2007) findings that students do not like to mix their personal virtual space with their study virtual space. Here is the comment:

I don't think it's a good idea, cos facebook is more or less for entertainmenet it is not nice to have studies and entertainment in one place.

This difference between the studies may be due to the more recent addition of Facebook settings to afford all users greater privacy. More positive comments were:

Facebook is a good use for practical write ups and tutorials; Facebook has really helped... because class mates have submitted questions and answered; There was a time when I got stuck with my practical write ups but facebook came to the rescue.

Responses to a question about the use of student e-champions were positive and identified specific ways in which they had helped:

... being able to ask any questions I had and learning from other questions that other students asked and...having other students available to discuss the module with.

Students also said they appreciated the sharing of lecture notes.

\section{Interviews with lecturers and the student e-champions}

The module leaders liked the mediating role the e-champions played between themselves and the students, for example: 
They created a better dialogue with the students and were a conduit for more discussions and two-way interactions with the students.

The e-champions were most successful in eliciting for the class a list of troublesome points which they wished me to clear up.

One module leader articulated three benefits of the partnership. These were: i) that they were 'icing on the cake', and whilst they had not saved him any time, they had supplemented the learning on the module in a way which he wouldn't have been able to; ii) that seeing the Facebook discussions gave him more of a 'feel' for his students and their progress, enabling him to adjust his teaching; and that, iii) he felt that his students appeared more willing to raise and communicate questions, problems, issues about their learning in the Facebook space, than they were directly to him. The other module leader thought that his e-champions got a bit carried away in creating new materials and suggested in future there should be a clearer brief and more joint planning. Both module leaders felt that the intervention added value and are willing to proceed to a further cycle of experimentation.

The five student e-champions all reported that they: i) had achieved more on the module than they would have if they had not been e-champions; (ii) would have liked more time; (iii) enjoyed the role; (iv) were at times dismayed by the apathy of their peers; and (v) felt that the e-champion role was acceptable to their peers. Recruiting students in roles such as peer assisted mentor, or in our case e-champions, always raises ethical questions about privileging some students over others. So long as the selection is fair and transparent, the advantages of participating in schemes such as ours are no different to those gained from student volunteering generally (see for instance the Peer Assisted Scheme in Manchester http://www.campus.manchester.ac.uk/tlso/studentsaspartners/) where benefits to the students include increased academic performance. Some students elected to engage with the e-champions and others did not and this also reflects differential learner engagement generally. What adds to the ethical complexity in our case is that unlike Peer Assisted Learning Schemes such as those in Bournemouth (http://pal.bournemouth.ac.uk/index.html) and Manchester, our e-champions are part of the cohort they are supporting, and are empowered to choose the supportive technology. Our ongoing action research continues to be alert to this complexity. 


\section{Discussion}

We return to the four, interconnected, $180^{\circ}$ changes for the 'e' side of blended learning provision which we suggested at the start.

(i) The choice and development of technologies used can be made by learners.

(ii) This choice can be from common, freely available, student understood technologies which are in the public domain.

This study shows that Web 2.0 spaces which are familiar to, and were thus chosen by the e-champions were equally, or more, useful technologies, than VLEs. Indeed maybe they are more likely to engage our students across a wider range of useful learning related activities than institutionally owned ones. For example, no posts to either VLE forum, yet a large number of posts to Facebook groups. Why was this? It might have been because the Facebook group was set up, owned and directed by peers they felt less judged, and it replicated informal situations. It is also likely that the use of Facebook blurred the boundaries between the social and formal learning on-line spaces. Where there was a functionality which Facebook could not support, the e-champions easily found other suitable technologies, and posted links to them. The increased learner engagement as compared to the VLE, the variety of new types of peer-peer and partnership generated learning activities, and that the technologies used were cost neutral, all make a strong argument for the use of free, student understood and led, web 2.0 technologies to house 'e' support. This is a key finding, and one that contradicts Dohn (2008) and Ryberg (2008) who reported tensions when institutions infiltrated students' virtual social spaces. It is likely explained by the recent, enhanced privacy settings implemented by Facebook, which subsequently allowed users much tighter control over who is able to access their personal information therein.

No learning activities that can be created in a VLE or an e-portfolio, cannot equally be provided using free technology. This has beneficial cost implications for institutions, regarding software licenses, software and hardware support, together with staff development. The analysis concurs with Hemmi et al.'s (2009, p.1) findings of '.... a range of student and tutor perspectives which show that these technologies have significant potential as new collaborative, volatile and challenging environments for formal learning'. 
(iii) The creation of technological support can be done by students in partnership with academics.

(iv) That the production of these opportunities be done by incentivised students.

The Melville Report 'Higher Education in a Web 2.0 World' (2009, p.7) suggests many of the changes in ' $e$ ' support which our project has enacted, specifically the nature of partnership in the 'e' enterprise, '... where each recognises and values the others' expertise and works together to capitalise on it'. This study shows that such a partnership can work to the benefit of learner and academic. Many of the learning opportunities created in this project resulted from the instinct and instigation of the student e-champions and were generated from their leadership of a virtual space. They additionally formed a communication channel between staff and students which, whilst not a technical role, improved communication flows and enabled teaching to be adjusted and problems to be addressed. We would argue that the learning leadership, control, decisions, and nature of 'e' support be placed with students, working in tandem with academics.

\section{Conclusion}

Our analysis of Facebook gave us and their tutors a window into the habitus (Bourdieu and Passeron, 1977) of our students. In other words, it made clear to us a set of dispositions held by the students, namely a keenness to get things right, to expand their learning, to get closer to the tutors and to share their hesitancies, knowledge gaps and questions. The mediating role of the e-champions proved particularly useful in bringing together the worlds of the academic and that of the students. Importantly, our intervention showed students' willingness to accept the structured peer support of the e-champions and the willingness of academics to give up a measure of control to the e-champions. We are encouraged to progress our exploration with further action research cycles. Key modifications will involve a facilitated design event with tutors and e-champions attending together to include a revised evaluation strategy. We will also need to address the evidence that the digital divide is more likely to affect the poorest sections of our society (Fearn, 2008) rather than our student body, but we cannot take this for granted. Moreover, a good number of university students do not typify the generation we have described, being older or in subjects where the emphasis is on working with hand rather than with mouse. We will also need to be mindful of: i) how institutions would deal with 
unacceptable interactions in publicly owned spaces; ii) the lack of student e-champion awareness of productive pedagogical applications of technology; and iii) with e-champions, the issue of possible factually erroneous posts.

To summarise, we have argued for a paradigm shift in the shaping of student learning to take account of peer-peer and teacher-peer partnerships beyond those owned, supervised and instigated by institutions (e.g. PAL at Bournemouth University), the free and familiar technologies, and the changing nature of our student bodies' skills. Our first action research results prompt us to continue our explorations and we hope that our report encourages others to replicate our thrust.

\section{References}

Bourdieu, P. and Passeron, J.C. (1977) Reproduction in education, society and culture. Richard Nice (tr.). London: Sage Publications.

Browne, T., Hewitt, R., Jenkins, M. and Walker, R. (2008) Survey of technology enhanced learning for higher education in the UK. UCISA. Available at: http://www.ucisa.ac.uk/publications/tel survey.aspx (Accessed: 10 February 2011).

Cann, A.J. (2008) Web 2.0 comes of age: disintermediation and the long tail in higher education. Available at:

http://www.heacademy.ac.uk/resources/detail/events/annualconference/2008/Ann C onf 2008 Alan Cann (Accessed: 10 February 2011).

Centre for Educational Research and Innovation (2008) New millennium learners. Initial findings on the effects of digital technologies on school-age learners. Available at: http://www.oecd.org/dataoecd/39/51/40554230.pdf (Accessed: 11 February 2011).

Cvetkovic, V. and Lackie, R. (2009) Teaching generation M: a handbook for librarians and educators. New York: Neal-Schuman Publishers Inc. 
Dohn, N.B. (2008) 'Knowledge 2.0 - tensions and challenges for education', Proceedings of the 6th International Conference on Networked Learning. Halkidiki, Greece 5-6 May. Available at:

http://www.networkedlearningconference.org.uk/past/nlc2008/abstracts/PDFs/Bond erup Dohn 650-657.pdf (Accessed: 11 February 2011).

Fearn, H. (2008) 'Grappling with the digital divide', Times Higher Education Supplement, 14 August, (Online). Available at:

http://www.timeshighereducation.co.uk/story.asp?storycode=403135 (Accessed: 11 February 2011).

Hemmi, A., Bayne, S. and Land, R. (2009) 'The appropriation and repurposing of social technologies in higher education', Journal of Computer Assisted Learning, 25, pp. 19-30.

Hockings, C., Cooke, S. and Bowl, M. (2007) 'Academic engagement within a widening participation context - a 3D analysis', Teaching in Higher Education, Special Issue: Diversity and Commonality in Higher Education, 12(5-6), pp. 721-734.

JISC (2007) Learners' experiences report. Available at: http://www.jisc.ac.uk/elp learnerexperience (Accessed: 11 February 2011).

Kerawalla, L., Minocha, S., Kirkup, G. and Conole, G. (2009) 'An empirically grounded framework to guide blogging in higher education', Journal of Computer Assisted Learning, 25(1), pp. 31-42.

Lingard, L. (2007) Why don't all lecturers make use of VLEs? What can the so-called 'Laggards' tell us? Available at: http://clt.Ise.ac.uk/reportsPubs/ReportLingardFinal.pdf (Accessed: 11 February 2011).

Melville, D. (2009) Higher education in a Web 2.0 world: report of committee of enquiry into the changing learner experience. Available at: http://www.jisc.ac.uk/media/documents/publications/heweb20rptv1.pdf (Accessed: 9 February 2011). 
Minocha, S. (2009) A study on the effective use of social software by further and higher education in the UK to support student learning and engagement. Available at: http://www.jisc.ac.uk/media/documents/projects/effective-use-of-social-software-ineducation-finalreport.pdf (Accessed: 11 February 2011).

Newland, B., Jenkins, M. and Ringan, N. (2006) 'Academic experiences of using VLEs: overarching lessons for preparing and supporting staff', in O'Donoghue, J. (ed.) Technology supported teaching and learning: a staff perspective. London: Information Science Publishing, pp. 34-50.

Prensky, M. (2001) 'Digital natives, digital immigrants', On the Horizon 9(5). Lincoln: NCB University Press.

Ryberg, T. (2008) 'Challenges and potentials for institutional and technological infrastructures in adopting social media', Proceedings of the 6th International Conference on Networked Learning. Halkidiki, Greece 5-6 May Available at: http://www.networkedlearningconference.org.uk/past/nlc2008/abstracts/PDFs/Ryber g 658-665.pdf (Accessed: 11 February 2011).

Sharpe, R., Benfield, G., Roberts, G., and Francis, R. (2006) The undergraduate experience of blended e-learning: a review of UK literature and practice. Available at:

http://www.heacademy.ac.uk/assets/York/documents/ourwork/research/literature re views/blended elearning full review.pdf (Accessed: 11 February 2011).

Traxler, J. (2009) Students and mobile devices: choosing which dream. Available at: http://repository.alt.ac.uk/643/1/ALT-C 09 proceedings 090806 web 0288.pdf (Accessed: 11 February 2011).

Trentin, G. (2009) 'Using a wiki to evaluate individual contribution to a collaborative learning project', Journal of Computer Assisted Learning, 25, pp. 43-55. 


\section{Author details}

Dr Paul Brett is Head of Blended Learning at University of Wolverhampton and a NTF. He leads a team of five Blended Learning Advisors, based in the Institute for Learning Enhancement. He has published extensively on the use of technology to enhance learning and was the first Chair of the Heads of e-Learning Forum (HeLF).

Professor Glynis Cousin is Director of the Institute for Learning Enhancement. She was previously a Senior Advisor at the Higher Education Academy and has worked in adult, community and higher education. Her recent book Researching Learning in Higher Education has just been published by Routledge. 